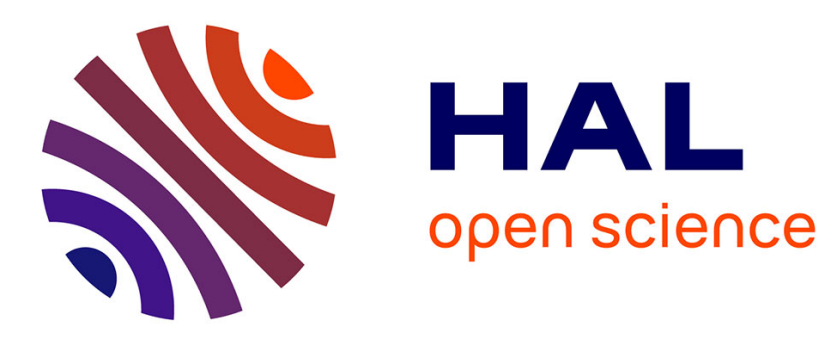

\title{
Humidity Sensing using Soft Ferrites
}

A. Vaingankar, S. Kulkarni, M. Sagare

\section{To cite this version:}

A. Vaingankar, S. Kulkarni, M. Sagare. Humidity Sensing using Soft Ferrites. Journal de Physique IV Proceedings, 1997, 07 (C1), pp.C1-155-C1-156. 10.1051/jp4:1997155 . jpa-00255102

\section{HAL Id: jpa-00255102 https://hal.science/jpa-00255102}

Submitted on 1 Jan 1997

HAL is a multi-disciplinary open access archive for the deposit and dissemination of scientific research documents, whether they are published or not. The documents may come from teaching and research institutions in France or abroad, or from public or private research centers.
L'archive ouverte pluridisciplinaire HAL, est destinée au dépôt et à la diffusion de documents scientifiques de niveau recherche, publiés ou non, émanant des établissements d'enseignement et de recherche français ou étrangers, des laboratoires publics ou privés. 


\title{
Humidity Sensing using Soft Ferrites
}

\author{
A.S. Vaingankar, S.G. Kulkarni* and M.S. Sagare** \\ Shivaji University, Kolhapur 416 004, India \\ * Willingdon College, Sangli 416415 , India \\ **BV's ASC College, Sangli 416416 , India
}

\begin{abstract}
The electrical properties of polycrystalline soft ferrites, namely $\mathrm{Cu}-\mathrm{Zn}$ system are considerably changed by doping controlled amounts of Lithium and Calcium salts. The room temperature resistivity is found to exceed $1000 \mathrm{M} \boldsymbol{\Omega} \mathrm{cm}$ at $45 \%$ relative humidity. Variation of resistivity with percentage relative humidity is found to be linear in the range above $60 \% \mathrm{RH}$ and is of the type $P=\rho_{0}-\mathrm{MRH}$. M being a slope of the curve which is humidity sensitivity. In the range 45 to $60 \% \mathrm{RH}, \log \rho$ Vs $\% \mathrm{RH}$ exhibits linear relation and is governed by the nature $P=P_{0 e}-k r h . K$ being humidity sensitivity. The statistical tools are employed for the analysis of the curves and all the parameters are tested giving best results. The response time in the disc form, for both negative and positive step is of the order of 6 to 7 seconds for $5 \%$ change while it is of the order of 7 to 8 minutes for -ve step and one minute for +ve step for $45 \%$ to $85 \%$ change in RH. The material does not exhibit any aging effect. In the entire range of humidity, the pellets do not become watery. Basically, ferrites are temperature sensitive and therefore, humidity and temperature sensing both can be done in a single device, because there is no any effect of humidity on the magnetic properties of these materials.
\end{abstract}

\section{Introduction :}

Conventional humidity sensors are slow, less sensitive and therefore, less reliable and suffer from large hysteresis effects. Use of ferrites as temperature sensors is well known. Kyoshiro Seki et. al. (1) have reported use of TSFs as humidity sensors. Humidity dependent properties of ferrites are shown to be enhanced by doping controlled percentages of alkali ions (2). One more advantage of using ferrites is that, they can be porous and porosity is the basic need of a humidity sensor. In the present communication, humidity dependent properties of $\mathrm{Zn} 0.8 \quad \mathrm{Cu}_{0.2} \quad \mathrm{Fe}_{2} \mathrm{O}_{4}$ doped with $0.01 \%$ of $\mathrm{CaCl}_{2}$ and $\mathrm{LiCl}$ are reported.

\section{Experimental :}

Each composition of the system $\mathrm{Zn}_{\mathrm{X}} \mathrm{Cu} 1-\mathrm{x} \mathrm{Fe}_{2} \mathrm{O}_{4}$ with $\mathrm{X}=0.2,0.4,0.6$ and 0.8 is doped with $0.01 \%$ $\mathrm{LiCl}$ and $\mathrm{CaCl}_{2}$. Samples in the form of pellets of $1 \mathrm{~cm}$ diameter and about $0.2 \mathrm{~cm}$ thickness were prepared by standard ceramic technique. Resistances of samples at various \% Relative humidities are measured by using digital insulation meter at a constant dc voltage of 250 Volts. Time response of the sample is observed for a step change of $\pm 5 \%$ and $\pm 40 \% \mathrm{RH}$.

\section{Results and Discussion :}

The de resistivities of $\mathrm{Zn} 0.8 \mathrm{Cu} 0.2, \mathrm{Fe}_{2} \mathrm{O}_{4}$ doped with $\mathrm{CaCl}_{2}$ and $\mathrm{LiCl}$ are found to decrease with increase in \% Relative humidity as shown in fig. The graph clearly shows that decrease in resistivity with increase in $\% \mathrm{RH}$ is very large from $45 \%$ to $60 \% \mathrm{RH}$. In this range, the graph of $\mathrm{Ln}(\rho) \mathrm{Vs} \% \mathrm{RH}$ is a straight line having negative slope, which indicates that in this range, resistivity drops exponentially with increase in $\% \mathrm{RH}$. The relationship between $\mathrm{R}$ and \%RH is governed by equation

$$
\rho=\rho_{0} \text { e }-K R H
$$

Here $K$, the slope of $\operatorname{Ln}(\rho)$ Vs \%RH curve is regarded as humidity sensitivity. In higher humidity range i.e. above $60 \% \mathrm{RH}$, variation of resistivity with \%RH is found to be linear and is given by equation

$$
\rho=\rho_{0}-\mathrm{MRH}
$$

The slope of straight line i.e. ' $\mathrm{M}$ ' is regarded as humidity sensitivity in this range. 
For the statistical analysis, lines of regression are fitted for values of $\mathrm{Ln} \rho$ and $\% \mathrm{RH}$ in the range of $45 \%$ to $60 \% \mathrm{RH}$ and for the values of $\rho$ and $\% \mathrm{RH}$ above $60 \% \mathrm{RH}$. For both the regression lines, the correlation coefficient is greater than 0.99 ; indicating excellent correlation. The value of ' $t$ ' parameters are 68.28 and 22.16 for the samples doped with $\mathrm{CaCl}_{2}$ and $\mathrm{LiCl}$ respectively, indicating a confidence level greater than $99.9 \%$ which also corresponds to perfect fitting of regression lines to the observed data and the values of rho estimated from these lines are in excellent agreement with actual values.

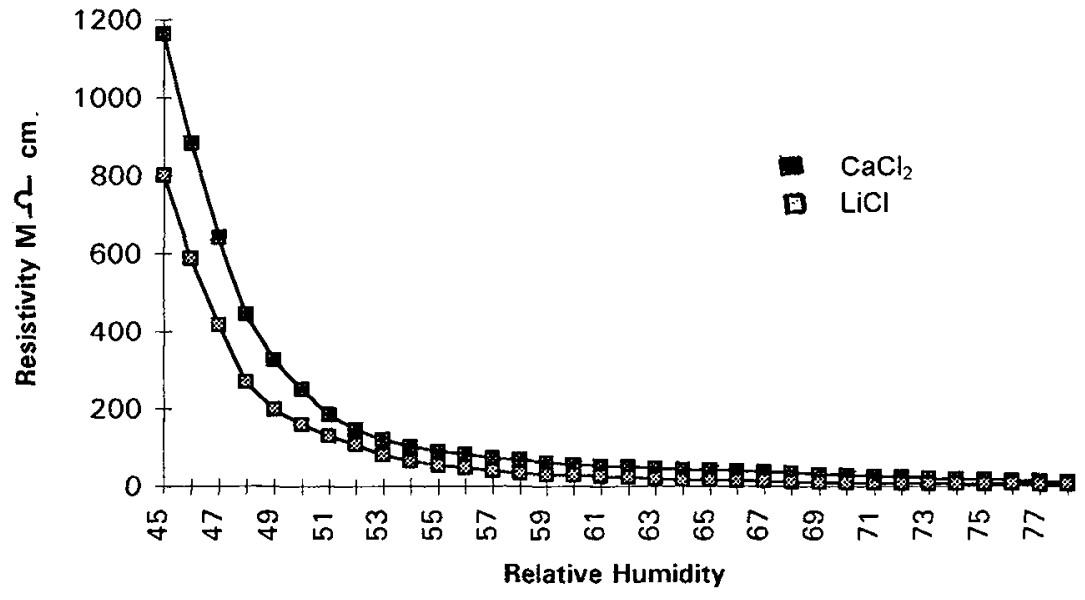

Response timie for a step change of $5 \% \mathrm{RH}$ is about 5 to 6 seconds for both positive and negative steps, indicating a fast responce and low hysterisis lag. However, for a positive step change from $45 \%$ to $85 \% \mathrm{RH}$, the response time is about 1 minute and for the same negative step it is 6 to 7 minutes, which is still better as compared to many available alternative sensors in market. It is further observed that the samples do not become watery even after a long time exposure to humidities as high as $85 \%$ and show exactly similar results even after one year, indicating no aging effect.

\section{Conduction Mechanism in Humid Conditions :}

Hygroscopic dopants like $\mathrm{CaCl}_{2}, \mathrm{LiCl}$ try to maintain a constant humidity level in their viscinity provided by that they are in a saturated solution in presence of excess of their solids. At lower humidities, if \% $\mathrm{RH}$ in their viscinity is increased, large anount of water is absorbed and hence drop in resistivity is larger. However, at higher humidities, concentration of dopants becomes relatively smaller and solution no longer remains saturated, and hence, less quantity of water is absorbed, which causes small change in resistivity with \% $\mathrm{RH}$. At lower humidities, the conduction may be due to phonon induced tunneling as suggeted by Starts H. et.al.(3) and at higher humidities, it may be due to Protonic conduction and capillary condensation of water into microporous as suggested by Robert A Marra (4). Conduction in humid condition is also attributed to semiconductor mechanism in which electronic conductivity and carrier concentration changes with amount of Chemisorbed water (4). In the present system, more number of charge carrriers are introduced due to dissociation of $\mathrm{CaCl}_{2}$ or $\mathrm{LiCl}$ into constituent alkali and $\mathrm{Cl}^{-}$ions due to their reaction with absorbed water.

\section{References :}

(1) Kyoshiro Seki, Jun-Ichi Shida and Koichi Murakami, IEE Transactions on Instrumentation and Measurements, Vol 37 No.3 Sept. 1988.

(2) T.Okamoto, T.Suzuki and N Matsui, J Phys Colloq. Vol 47, No C-8 pt 2, P 737-40.

(3) Starts H. and De Mars.G.A., Phys Rev. 111169 (1958).

(4) Robert A Marra. J Am. Ceram Soc. 69 (7) C 143-45 (1986) 